\title{
NIÑOS MIGRANTES EN MÉXICO Y EL CUMPLIMIENTO DEL DERECHO HUMANO A LA EDUCACIÓN
}

\section{MIGRANT CHILDREN IN MEXICO AND THE FULFILLMENT OF THE HUMAN RIGHT TO EDUCATION}

\author{
Rosa Cornelio Landero \\ Universidad Juárez Autónoma. Tabasco / México \\ https://orcid.org/0000-0002-0300-6702 \\ rosecorlan@hotmail.com
}

Recibido/Received: 07/06/2019

Modificado/Modified: 17/09/2019

Aceptado/Accepted: 26/09/2019

\section{RESUMEN}

El territorio mexicano se encuentra en la mira de las organizaciones internacionales que protegen los derechos humanos, ante la alza de flujo migratorio que van a los EEUU., los niños migrantes y su situación en el territorio mexicano que viajan en caravanas solos o con sus padres, son los más vulnerables por su corta edad a ser víctimas de violencia, trata de personas y abuso sexual, por lo que son los que requieren mayor atención y ayuda humanitaria, no discriminarlos por ninguna circunstancia; la UNICEF México es un organismo que busca la protección de los niños, que tengan un trato digno, que se le otorgue sus derechos humanos como son: a la salud, a la educación, todos los que señalan las normas protectoras de los derechos humanos internacionales y nacionales y que son inherente a las personas; por lo que el Estado mexicano debe crear políticas públicas en materia de derecho humano sobre todo para los niños migrantes.

\section{PALABRAS CLAVE}

Niños; migración; Derechos Humanos; grupo vulnerable; educación.

\section{SUMARIO}

1. Introducción. 2. Los niños migrantes y su situación en el territorio mexicano. 3. El derecho humano a la educación. 4. Leyes mexicanas y políticas públicas en materia de derecho humano a la educación de los migrantes. 5. Conclusiones. Bibliografía.

\begin{abstract}
The Mexican territory is in the sights of international organizations that protect human rights, given the increase in migratory flow to the US, migrant children and their situation in the Mexican territory traveling in caravans alone or with their parents, are the most vulnerable because of their young age to be victims of violence, trafficking in persons and sexual abuse, so they are the ones that require the most attention and humanitarian aid, not discriminate against them under any circumstances; UNICEF Mexico is an organism that seeks the protection of children, that they have a dignified treatment, that their human rights be granted, such as: to health, education, all those that indicate the norms that protect
\end{abstract}


international human rights and national and that are inherent in people; Therefore, the Mexican State must create public policies regarding human rights, especially for migrant children.

\section{KEYWORDS}

Children; Migration; Human Rights; Vulnerable group; Education.

\section{CONTENTS}

1. Introduction. 2. Migrant children and their situation in Mexican territory. 3. The human right to education. 4. Mexican laws and public policies on the human right to education of migrants. 5 . Conclusions. References.

\section{INTRODUCCIÓN}

Los grupos de migrantes que transitan por el territorio mexicano, es un fenómeno que cada día es más latente, el recorrido que hacen las personas de la frontera sur a la frontera norte es complicado, en donde sufren diversos tipos de conflictos; la búsqueda de una mejor forma de vida los ciudadanos guatemaltecos, hondureños, salvadoreños, los lleva a enfrentar todo tipo de peligros, hasta llegar a su destino final que siempre es Estados Unidos de Norte América.

La situación económica actual y los conflictos sociales hacen que las familias salgan de sus países de origen, la información que proporcionan los medios de comunicación, las instituciones gubernamentales mexicanas, es que cada vez son más grandes los grupos o caravanas de migrantes, en los que van los integrantes de las familias, cada vez los índices de niños y niñas son altos. Los niños son propensos a ser agredidos por los grupos delictivos, violando sus derechos humanos, sufriendo inclusive de abusos sexuales, ante la falta de recursos y de compromisos de las instituciones mexicanas hace que los niños migrantes sufran por la falta de sus derechos humanos.

El compromiso adquirido por el Estado mexicano, lo hace responsable de buscar estrategias y programas para dar complimiento a lo establecido en los instrumentos internacionales y la misma Constitución Política de los Estados Unidos Mexicanos, de hacer que toda persona sin distinción alguna haga valer sus derechos humanos; en el caso del derecho a la educación aún no cuenta con las políticas públicas suficientes para brindar educación a los niños migrantes.

\section{LOS NIÑOS MIGRANTES Y SU SITUACIÓN EN EL TERRITORIO MEXICANO}

Los niños migrantes al ser indefensos están considerados dentro del grupo vulnerable, ya que son los que viven circunstancias agresivas para su edad, presentan necesidades especiales, son expuestos a agresiones que no pueden defenderse solos, a tratos no dignos, en el caso de las niñas son las que sufren los actos de violencia, abusos sexuales. En el caso de los niños que viajan en grupos o caravanas padecen de agresiones, enfermedades esto debido a las circunstancias y condiciones inhumanas.

México enfrenta el fenómeno de la migración en masa, ya que es un paso de las personas que van como migrantes al país vecino del norte, personas de diversas nacionalidades buscan ingresar de forma legal e ilegal a los EEUU, por lo que tienen que transitar por toda la frontera de México, de nacionalidades sobre todo de los países que son vecinos de las 
frontera sur, como Guatemala, Honduras, El Salvador, hasta personas de otros países origen asiáticos, que utilizan la frontera sur de México para ingresar y transitar hasta llegar a su destino final el norte para entrar a EEUU, durante ese tránsito sufren de vejaciones, agresiones, violaciones, discriminación de todo tipo.

La situación de los niños migrantes que provienen del llamado Triángulo Norte de América Central en las que se encuentran Guatemala, Honduras y El Salvador, de donde los menores salen por temor a la violencia generada por grupos que se dedican a delinquir, para buscar mejores oportunidades desarrollo económico o para reunirse con sus familias en México $o$ en Estados Unidos, tienen que enfrentar diversos tipos de violencia y discriminación al entrar en el territorio mexicano. Está un poco lejos de la realidad a lo que señalan las normas jurídicas protectoras de los derechos humanos, ya que los migrantes sufren de violación a sus derechos humanos, como señala Alfredo Islas, "en la frontera sur la discriminación motivada por la raza, color, origen nacional o social, idiomas, nacimiento, edad, sexo, orientación sexual, identidad de género" (Islas, 2018:35).

El problema con relación al control migratorio en las fronteras mexicanas, se complica cada día, ante la falta de políticas públicas y que las organizaciones sean responsables en su labor; un punto fuerte es que se han generalizado las situaciones de violencia, que ha provocado el aumento de personas transitando de forma clandestina enfrentando zonas peligrosas, viajan arriesgando su propia vida, en las que sufren de enfermedades de toda clase; es un fenómeno social que no solo se vive en México, sino también en diversas partes del mundo, en el año 2018, el territorio mexicano vivió el paso de grupos de migrantes en masa, la caravana que salió de Honduras con miras de llegar a EEUU.

Los grupos de migrantes centroamericanos que ingresaron por las fronteras mexicanas en los que viajaban menores de edad, se ventilo en los medios de comunicación que más de 2000 niños viajaban en la caravana y que eran los más vulnerables de ser víctimas de violencia, en el mes de octubre de 2018, un grupo demasiado grande ingresaba a México en donde se vivieron de todo tipo de violencia, los medios de comunicación le dieron seguimiento al tránsito del grupo enorme de personas como es el The New York Times en su nota del 22 de octubre de 2018 señala;

"Una caravana de cientos de migrantes centroamericanos había atravesado México a pie algunos meses antes para tratar de entrar a Estados Unidos. Los funcionarios estadounidenses querían saber si México estaría de acuerdo con obligar a esos migrantes a solicitar asilo en ese país, en vez de dejarlos entrar a Estados Unidos" (Ahmed y Dickerson, 2018).

Los migrantes durante el paso de la frontera sur a la frontera norte, como es el caso de los niños y niñas han tenido que enfrentar la violencia que se vive en nuestro país, en los que no pueden defenderse por sí solos, situación que tienen en mente cada persona migrante más en el caso de los padres que llevan a niños tienen que enfrentarse por los niños, ya que son los que pueden ser atacados por los grupos delictivos que se desplazan en las zonas por donde transitan, a lo largo de su camino por el territorio mexicano se enfrentan a diversos peligros. Mientras que en la frontera con EEUU son detenidos y deportados de ese país, los estados mexicanos que son parte de la frontera norte, sufren de sobrepoblación, empiezan a vivir otros problemas sociales como es el desempleo, prostitución, violencia, discriminación en los que migrantes en ocasiones son relacionados y no tienen como defenderse por no contar con documentación.

Los grupos de migrantes durante la última década se ha visto el creciente número de menores que viajan a la frontera norte de México, en el caso de niños acompañados con algún familiar, pero lo más preocupante es que los niños que viajan solos y transita por el territorio mexicano, ha preocupado a los organismos internacionales, debido a que las 
autoridades mexicanas no cuentan con las medidas y políticas necesarias para que les proporcionen el trato que se merecen los niños y niñas. En el informe anual de actividades (Informe, 2018) de la Comisión Nacional de Derechos humanos (CNDH), señala que "de las 88.741 personas extranjeras presentadas hasta noviembre de 2017, 16.694 fueron niñas, niños y adolescentes, de los cuales 6.866 eran niñas, niños y adolescentes no acompañados.

La situación de los niños migrantes durante el tránsito por el territorio mexicano, es complicada, tienden a ser discriminados los que son irregulares, en caso de niños no acompañados se les complica al transitar de la frontera sur a la frontera norte de México, al grado que son presa para los delincuentes, lo que se vive en México por ser un país de origen, tránsito, y destino de los grupos de migrantes. Organismos como la Comisión Nacional de los Derechos Humanos (Informe, 2018) señalan en sus informes especiales, recomendaciones y pronunciamientos su preocupación e inquietud por la situación de vulnerabilidad que atraviesan los grupos de personas que se encuentran en situación de migración.

La discriminación y violencia que viven actualmente los niños y niñas migrantes al intentar llegar a EEUU, la violación a los derechos humanos de los funcionarios encargados de las instituciones migratorias de México, ante el robo, secuestro, trata de persona; aun y cuando sufren esas vejaciones no se pueden quejar ante el temor a ser atacados o desaparecidos como ha pasado con sus compatriotas, la falta de acceso a los servicios básicos en caso de enfermedad o accidente para que puedan ser atendidos en algún centro médico; el acceso a la justicia, durante el tiempo en que se encuentren en algún refugio o estén detenidos por el Instituto Nacional de Migración es que los niños reciban clases, atención de maestros que puedan ayudarles a aprender a leer, escribir, etc.

El tema de niños migrantes es una preocupación, ya que necesitan servicios y atención especial para la protección de sus derechos humanos, son parte del grupo vulnerable que necesita cuidados especiales, por la condición de ser menores de edad están expuestos a que cualquier persona o grupo los maltrate, abuse o explote, a ser víctimas de los grupos delictivos agreden a los migrantes en el tránsito por el territorio mexicano, sufriendo inclusive los cambios climáticos, que acarrean las enfermedades, los accidentes, pero lo preocupante es que esos niños al salir de su país de origen dejan sus estudios y mientras están en calidad de migrantes no se les proporciona el derecho humano a la educación. Es necesario que las autoridades mexicanas establezcan políticas públicas reales que sirvan para que los niños en esas condiciones puedan disfrutar de los derechos humanos.

En los últimos años gran parte de los migrantes que transitan por el territorio mexicano son niños y niñas, que salen de los países de Honduras, Guatemala, El Salvador, siendo su destino final los Estados Unidos, muchos de ellos son víctimas de la violencia en su trayecto por el territorio, de acuerdo al información del Instituto Nacional de Migración (INM), durante los meses de enero-abril de 2018, tan solo en el mes de abril los niños y niñas migrantes detenidos por el INM fueron 2.596; a diferencia de abril de 2019 la cantidad se elevó a 6.842, en comparación al año 2018, esta información es solo de la estadística de niños y adolescentes acompañados y no acompañados que fueron presentados ante la autoridad migratorio en México.

No se tiene registrada una cantidad exacta de los niños migrantes, ya que no todos son detenidos, esto quiere decir que la cantidad puede ser más elevada, por los que aún no han sido identificados, los migrantes que transitan por el territorio nacional tienen los derechos humanos que son reconocidos por la Constitución Política de los Estados Unidos Mexicanos y los tratados internacionales firmados y ratificados por México, sin importar su nacionalidad ni situación migratoria, con especial atención a los grupos vulnerables como es el caso de los niños y niñas, quienes también tienen derecho a la educación. 
Tabla 1: Niños acompañados y no-acompañados, enero-abril 2018-2019

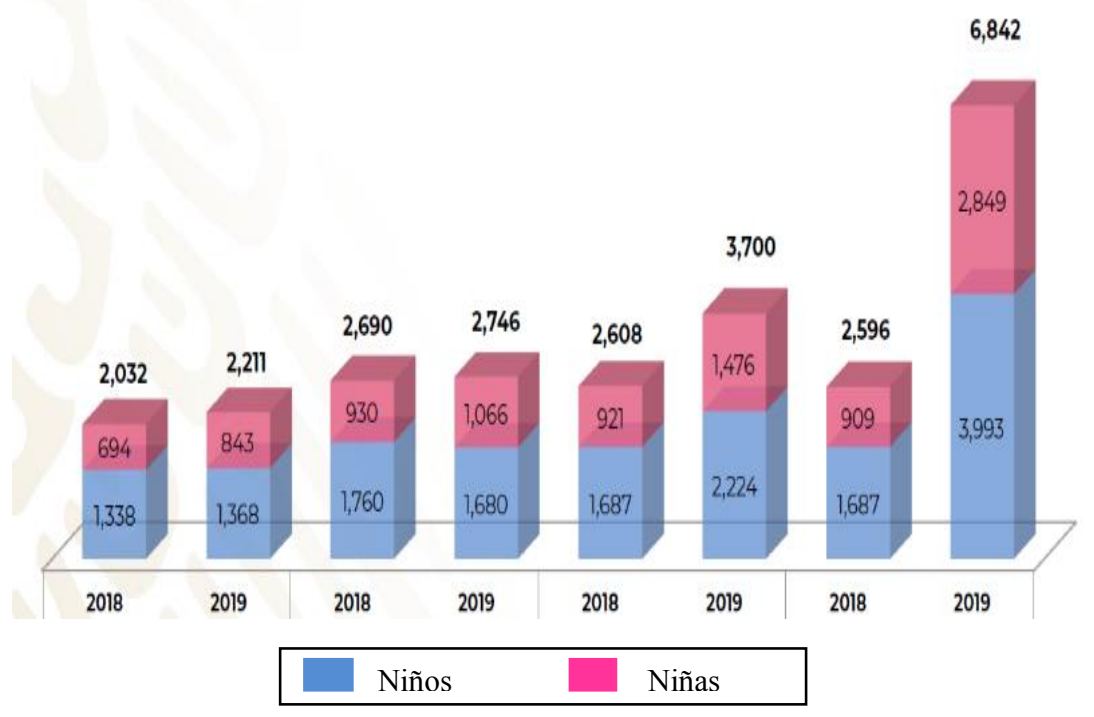

Fuente: Estadística de niñas, niños y Adolescentes (0 - 17 años) acompañados y no acompañados presentados ante la autoridad migratoria, enero - abril 2018 - 2019, Instituto Nacional de Migración (INM).

\section{EL DERECHO HUMANO A LA EDUCACIÓN}

La educación en México en la actualidad está pasando por transformaciones estructurales, con la mira de cambios para mejorar y trabajar en el rezago en que se encuentra. El derecho humano de los niños a una educación de calidad es esencial para que los países crezcan, en el caso de México en los últimos años ha logrado grandes avances, la cobertura es cada día más amplia, la preocupación de los organismos internacionales, como es el caso de las Naciones Unidas que promueve la aplicación de programas de Educación en Derechos Humanos en todos los sectores, para todos los niños sin excepción de personas, en el caso que nos ocupa los niños migrantes.

Los sistemas educativos en México han implemento programas que ayudan a alcanzar más espacios e implementar medidas que se pueda dar cumplimiento a lo establecido en el artículo 1 de la Constitución Política de los Estados Unidos Mexicanos, con la finalidad de lograr el objetivo de la educación inclusiva y que cumpla con la calidad, tratando de combatir todo tipo de violencia y discriminación, México busca crear programas que puedan acercarse a los niños que tienen problemas para recibir y disfrutar del derecho a la educación. Parte de los objetivos de la Reforma Educativa, de acuerdo al artículo 3ro de la Constitución Política de los Estados Unidos Mexicanos. Las preocupaciones de organismos internacionales con relación a los temas de educación y sobre todo dar a conocer la necesidad de implementar políticas públicas en educación a todos los niveles sociales y se hagan una realidad mundial.

La educación es tanto un derecho humano en sí mismo como un medio indispensable para realizar otros derechos humanos. Como un derecho de empoderamiento, la educación es el 
principal vehículo por el cual Los adultos y niños marginados económica y socialmente pueden salir de la pobreza y obtener los medios para participar plenamente en sus comunidades (Committee On Economic, Social and Cultural Rights, 1999: 1).

El reto de la educación de calidad es construir mecanismos que ayuden a que todos los niños puedan tener el acceso a recibir por lo menos educación básica; uno de los objetivos de los Derechos Humanos conllevan a que cada día se comprenda el verdadero concepto de los mismos, por lo que es importante buscar medidas y estrategias para que los educadores y sobre todo que los niños puedan tener el acceso a recibir educación, es un tema que atañe a nivel mundial que los Estados se comprometan a educar en Derechos Humanos. Los organismos internacionales tratan de cumplir con la responsabilidad de difundir y hacer valer los Derechos Humanos en todos los sentidos, para los que han invertido en programas a nivel mundial y que estos derechos sean conocidos desde los niveles básicos.

El 10 de diciembre de 2004, la Asamblea General de Naciones Unidas proclamó mediante resolución 59/113, el Programa Mundial para la educación en derechos humanos (2005-en curso) con el objeto de promover la aplicación de programas de educación en humanos en todos los sectores. El ACNUDH asegurará la coordinación internacional del Programa Mundial (ACNUDH, OHCHR, 2004).

Los Derechos Humanos en general y por lo que respecta al derecho humano a la educación es el punto esencial en la agenda de los organismos internacionales, con la insistencia de que les sea reconocido sin distinción alguna, estos organismos son quienes tienen el interés de dar mayor promoción a que todos somos poseedores de estos derechos; han creado diversos programas en todos los sectores para que la educación deba estar en el círculo o espacios de los derechos humanos. "Una educación en derechos humanos eficaz no sólo proporciona conocimientos sobre los derechos humanos y los mecanismos para protegerlos, sino que, además, desarrolla las aptitudes necesarias para promover, defender y aplicar los derechos humanos en la vida cotidiana" (Naciones Unidas, 2012: 2).

Los derechos humanos a la educación no son simplemente unos enunciados teóricos o de principios, todo lo contrario los seres humanos tienen que conocer sus derechos y saber respetar los derechos de los demás. Es por ello lo importante de enseñar desde la niñez los valores y principios que permitan la convivencia diaria de todos los individuos; que todas las instituciones educativas estén comprometidas a educar en derechos humanos, buscando la igualdad de todos ante la ley y ante la colectividad que conforman la nación y el estado, el compromiso de los Estados de respetar y hacer valer los derechos humanos sin distinción de raza, color, religión, sexo, etc., pero en la práctica no se vive realmente tal como está en la Constitución Federal y en los instrumentos internacionales.

Las Naciones Unidas mediante la Asamblea General aprobó "el Programa Mundial para la educación en derechos humanos, que comenzó el $1^{\circ}$ de enero de 2005" (Naciones Unidas, 2004). Con el interés de alentar a los Estados miembros a educar en derechos humanos; sin embargo en nuestra realidad aún existe atraso en la educación, debido a que las instituciones educativas, están centradas en lograr los indicadores de competencia, especialidades, por mencionar algunos, olvidándose en concientizar a los niños desde temprana edad los valores, la moral, es decir, el respeto a sí mismo y los derechos de los demás. En el caso de los niños que se encuentran en condición de migrantes por el territorio mexicano, no se les proporciona el derecho a la educación o por lo menos que se les imparta clases a los que se encuentra detenidos y pasan meses en los albergues, incluso hay muchos se quedan por años y pierden la educación básica.

Cada día se hace indispensable porque son ignorados o simplemente no se quieren aplicar de una manera adecuada. El artículo 3ro de la Constitución Política de los Estados Unidos 
Mexicanos, su objetivo es el de fomentar y hacer cumplir unos de los derechos humanos como es la educación, buscando el cumplimiento de los valores, pero para que esto suceda es necesario inculcar a las personas el amor y respeto los unos a los otros, convivir y fomentar la solidaridad en la sociedad, pero lo más fundamental es la admiración y respeto a los lábaros patrios, buscando la paz social. Es claro que está establecido en la Constitución Federal que todos tienen derecho a recibir educación, algo que el Estado mexicano ha pasado por alto para dar cumplimiento a dicho mandato constitucional.

La importancia de que los programas educativos en cualquier nivel tengan dentro de sus objetivos fundamentales, educar con valores, es para que los estudiantes puedan contribuir para la paz social dentro de cualquier comunidad donde tenga que desarrollarse. Bases firmes para que pueda ser un individuo que respete la diversidad y sobre todo saber convivir con ellos, atentos y responsables de sus actos, siempre respetando los derechos de las personas, que no exista discriminación de ninguna índole; que puedan formarse como individuos con mayor capacidad de interpretación de fenómenos, creatividad y manejo de la información en entornos cambiantes, el cambio de vida de su país de origen y acostumbrarse a otros hábitos, convivir con otros tipos de cultura en los que tienen que ser preparados.

La Constitución Política de los Estados Unidos Mexicanos, a partir de la reforma en junio de 2011, tiene establecido en el artículo primero, que está prohibido cualquier tipo de discriminación, ya sea por origen étnico o nacional, género, edad, discapacidad, condición social, de salud, religión, opiniones, preferencia sexual, estado civil o cualquier otra; pero a diario podemos escuchar o ser testigo de que los derechos humanos son violados, en el caso de los niños migrantes en el tránsito por la frontera mexicana, tienden a sufrir agresiones, violencia física o psicológica por los grupos delictivos, en ocasiones son por las mismas autoridades, hasta han perdido la vida por el hecho de no poder defenderse por su escasa fuerza física.

El derecho de igualdad es más que un derecho a no ser discriminado por género o por ser iguales ante la ley, en la actualidad ser discriminado, es porque se recibe un trato diferente, ya sea en el trabajo, en la escuela, en cualquier organización o grupo social. La escuela tiene que recuperar el lugar capaz para aprender y utilizar la infinidad de fuentes de información que nos obligan a replantear las capacidades que los alumnos deben desarrollar en su paso por la educación obligatoria, que les permitirá en su futuro una formación, humanismo, respeto y valoración a los demás, que crezcan con principios de igualdad y no discriminación por ninguna forma o circunstancia.

En México el modelo educativo basado en la reforma de la Constitución de fecha junio de 2011, en el artículo 1, señala la protección de todos los Derechos Humanos y las libertades, tomando en consideración el principio de la no discriminación se complementa con el principio de igualdad, tendremos una mejor cultura en los niños y jóvenes siendo mejores ciudadanos, pero que nos falta que el Estado se aboque a la creación de políticas públicas reales que puedan cumplir con lo señalado en nuestra Constitución Federal en su artículo, párrafo primero ." todas las personas gozarán de los derechos humanos reconocidos en esta Constitución y en los tratados internacionales de los que el Estado Mexicano sea parte" .

México al igual que muchos países buscan los medios para dar a conocer a la sociedad sus derechos humanos; pero la realidad que se vive es otra, un país con problemas de desaparición forzada, inseguridad, tortura, impunidad, todo esto hace que la sociedad perciba lo contrario a lo que en realidad son estos derechos, que han llevado a la reforma educativa a que se trabaje en temas de inclusión de los derechos humanos en cualquier tiempo o nivel educativo, la tardanza o decidía del Estado en educar en derechos humanos provoca que los niños, adolescentes y jóvenes caigan en las redes de grupos delictivos, por la falta de 
conocimientos. De acuerdo a Naciones Unidas los Derechos Humanos son "derechos inherentes a todos los seres humanos, sin distinción alguna de nacionalidad, lugar de residencia, sexo, origen nacional o étnico, color, religión, lengua, o cualquier otra condición" (ONU, 2017).

Los derechos humanos están integrados a los derechos civiles y son reconocidos en la primera generación; en la Convención Americana sobre Derechos Humanos, la cual fue suscrita en San José de Costa Rica el 22 de noviembre de 1969; para ser más específico en la Conferencia Especializada Interamericana sobre Derechos Humanos, en su artículo 4; advierte que "toda persona tiene derecho a que se respete su vida. Este derecho estará protegido por la ley y, en general, a partir del momento de la concepción. Nadie puede ser privado de la vida arbitrariamente" (CIDH, CADH, 1969).

Todos los Derechos Humanos por naturaleza tienen la misma importancia para las personas, porque están relacionados entre sí; pero sí tenemos que darle un privilegio al derecho de la vida y el derecho a la integridad personal, la vida del hombre en todos los tiempos se ha valorado y se ha ido perfeccionando hasta en nuestros tiempos, su valor es indiscutible, ya que parte de ella genera los otros derechos, para poder ejercerlos la persona necesita estar viva y gozar de ella, ser libre para tomar decisiones, es importante enseñar y educar en derechos humanos.

Para el cuidado de la integridad personal la Convención Americana sobre Derechos Humanos en su artículo 5, señala en el párrafo 2, lo siguiente: "Nadie debe ser sometido a torturas ni a penas o tratos crueles, inhumanos o degradantes. Toda persona privada de libertad será tratada con el respeto debido a la dignidad inherente al ser humano" (CADH, 1969). Por lo tanto los niños migrantes son poseedores de todos los derechos humanos por tanto tienen derecho a ser protegidos, el Estado está obligado a cumplir con ellas, dándoles la seguridad como personas, un trato digno; para que también gocen de los demás derechos que están relacionados entre sí.

La necesidad de proteger la vida a la persona, su integridad física, la libertad desde 1215 que aparecen por primera vez, estos derechos humanos, el principal derecho la vida, pero también que la persona viva con dignidad, así fueron apareciendo los otros derechos con la finalidad que toda persona tenga libertad para expresarse, transitar por cualquier territorio, a un trabajo digno, a poseer sus propiedad, recibir educación, la igualdad, la no discriminación, estos y los demás derechos tienen su razón de ser, y nunca ser violados por ningún motivo.

La relación que tienen todos estos derechos, si se violenta un derecho afecta de forma negativa los demás, los niños migrantes poseen derechos humanos, con el simple hecho de ser humano; la no discriminación es uno de los principios transversales que se encuentra señalados en el Derecho Internacional de los Derechos Humanos, que también es un tema central de muchas agendas de organismos internacionales y a la vez están en convenciones internacionales como tema principal.

La Declaración Universal de los Derechos Humanos en el artículo primero aporta un punto importante con relación a la dignidad e igualdad de todas las personas, tanto hombres como mujeres tenemos que saber vivir en cualquier sociedad respetando el derecho de los demás, para que reine la paz, dicho artículo hace hincapié en que "todos los seres humanos nacen libres e iguales en dignidad y derechos y, dotados como están de razón y conciencia, deben comportarse fraternalmente los unos con los otros" (ONU, DUDH, 1948).

Los derechos humanos se han reconocido por muchos países, ha existido el compromiso de los Estados como también a nivel mundial, garantizar los derechos humanos a todas las personas, por lo que se han creado diversas normas internacionales como normas protectoras 
de estos derechos, pero no solo queda ahí, sino también los Estados buscan acuerdos en diversos niveles, crean y reformas leyes para garantizar los derechos humanos a la educación y a los que se han comprometidos desde que se hacen parte de diversos acuerdos, tratados, convenios creados con tal finalidad, también es necesario contar con políticas públicas que puedan hacer llegar programas necesarios para hacer efectivo el cumplimiento de que todos los niños reciban la educación básica por lo menos. Pero en el caso que nos ocupa en especial de derechos humanos a la educación, a continuación, se mencionan algunos organismos e instrumentos internacionales que brindan protección:

1. Declaración Universal de los Derechos Humanos.

2. Declaración sobre los derechos humanos de los individuos que no son nacionales del país en que vive.

3. Pacto Internacional de Derechos Civiles y Políticos.

4. Protocolo Facultativo de los Derechos Civiles y Políticos.

5. Pacto Internacional de los Derechos Económicos Sociales y Culturales.

6. La Comisión de Derechos Humanos.

7. El Alto Comisionado para los Derechos Humanos.

8. La Relatoría Especial para los de los Derechos Humanos de los Migrantes.

9. El Sistema Regional de Promoción y Protección de los Derechos Humanos de los Trabajadores Migrantes.

10. Declaración Americana de los Derechos y Deberes del Hombre.

11. Convención Americana de los Derechos Humanos.

12. Protocolo Adicional a la Convención Americana en Materia de Derechos Económicos, Sociales y Culturales.

13. Comisión Interamericana de Derechos Humanos.

14. Relatoría Especial de Trabajadores Migratorios y Miembros de sus Familias.

15. La Corte Interamericana.

16. Comisión Nacional de Derechos Humanos.

17. Comisión Estatal de Derechos Humanos.

18. Agenda 2030

La importancia del derecho humano a la educación que estudia las causas de los problemas sociales y económicos del país, pero sobre todo está pendiente de que se dé cumplimiento, da los lineamientos para la creación de diversos programas que vayan acaparando los espacios que aun están alejados de sistemas educativos hasta alcanzar a los grupos vulnerables, en el caso de la educación para los niños migrantes aun México está atrasado para brindar y dar cumplimiento al compromiso contraído al firmar diversos instrumentos internacionales que protegen los derechos humanos. Faltan programas y políticas públicas que combatan los abusos contra los derechos humanos, la discriminación a personas en calidad de migrantes, que promuevan la igualdad.

La Constitución de la Organización de las Naciones Unidas para la Educación, la Ciencia y la Cultura, señala que "la amplia difusión de la cultura y la educación de la humanidad para la justicia, la libertad y la paz son indispensables a la dignidad del hombre y constituyen un deber sagrado que todas las naciones han de cumplir con un espíritu de responsabilidad y de ayuda mutua"; (UNESCO, 1945).

La educación de calidad que promueve la agenda mundial 2030, que señala lo importante que todos los niños y jóvenes tengan el acceso a una enseñanza de calidad y que es una obligación de los países garantizar el acceso a los sistemas educativos, pero algo que si es esencial es donde dice que debe ser equitativo, obligatorio y gratuita, para que las personas puedan desarrollarse de manera integral como personas, pero lo que nos debe de importar es 
la promoción a la comprensión, a la tolerancia y sobre todo a la paz.

México no debe pasar por alto que es un país comprometido con los ODS de la agenda 2030, en la Cumbre de las Naciones Unidas sobre el Desarrollo Sostenible celebrada en Nueva York con el fin de aprobar la Agenda para el Desarrollo Sostenible el 25 de septiembre de 2015 donde participaron más de 150 líderes mundiales se trabajó para "Transformar Nuestro Mundo: la Agenda 2030 para el Desarrollo Sostenible", tiene un compromiso, ya que fue uno de los países con mayor participación;

"México participó activamente en la definición de la Agenda. El país fue uno de los más activos en los foros de consulta, participando y liderando el proceso de negociación. No solo presentó propuestas puntuales para incorporar los principios de igualdad, inclusión social y económica, e impulsó que la universalidad, sustentabilidad y los derechos humanos fuesen los ejes rectores de la Agenda 2030”, (ONUMÉXICO, 2015).

La fuerza es un mecanismo que en diferentes partes del mundo o en cualquier sociedad se ha tomado como medida para construirla, sin ver que ésta cada vez se hace más violenta, permanece amenazada, que se nota cada día al ir dando pasos de reversa en el tejido social sin que se llegue a conseguir el progreso real hasta estos momentos. Nuestra realidad es que las personas aún viven actuando de manera violenta tratando de imponer actos o acciones para hacer ver que hay uno más fuerte que otro, que nada lleva a construir una sociedad en paz que es muy deseada y necesaria para el bienestar de la familia, la sociedad y progreso necesario para toda la humanidad.

El Fondo Internacional de Emergencia de las Naciones Unidas para la Infancia (United Nations Children's Emergency Fund: UNICEF) (UNICEF, 2002) UNICEF creo un programa que va a la escuela para construir una cultura de paz y solidaridad en el año 2002, haciendo hincapié en la "La Convención sobre los Derechos del Niño constituye un instrumento jurídico que modifica en forma profunda la concepción de la niñez y obliga al Estado, las instituciones, la familia y la comunidad a establecer nuevas formas de pensar y actuar sobre la infancia y la adolescencia". Es importante que tanto las instituciones educativas, la familia y la sociedad en general estén conectados para actuar en sus ámbitos para aportar al crecimiento de los niños y adolescentes, estableciendo diferentes mecanismos para construir una cultura de paz.

\section{LEYES MEXICANAS Y POLÍTICAS PÚBLICAS EN MATERIA DE DERECHO HUMANO A LA EDUCACIÓN DE LOS MIGRANTES}

La legislación mexicana está comprometida con los derechos humanos sigue creciendo y ampliando los derechos en el caso de la educación y libertades fundamentales, pero aún falta incluir en los sistemas educativos programas que enseñen los objetivos fundamentales de los Derechos Humanos, que ayuden a crear conciencia y vivir respetando a los demás, para que desaparezca la discriminación, las torturas, los niños violentados, personas en calidad de migrantes que no pueden ser incluidos en los programas a los que también tienen derechos; aunque quizás este en papel todavía, por la falta de capacidad de las autoridades responsables, así como de las instituciones encargadas de hacer que se respeten los derechos humanos, estas normas constituyen el marco para aplicación y respeto de los derechos de las niños y niñas migrantes y reflejan primordialmente los intereses de los Estados, de sus nacionales y las relaciones interestatales.

La falta de conciencia y educación de las personas que ejercen funciones en las instituciones. Entre las normas nacionales protectoras de los Derechos Humanos por 
mencionar algunas están:

1. Constitución Política de los Estados Unidos Mexicanos

2. Instrumentos internacionales- el derecho a la educación.

3. Ley general de educación

4. Ley General de Acceso de las Mujeres a una Vida Libre de Violencia

5. Reglamento de la Ley General de Acceso de las Mujeres a una Vida Libre de Violencia

6. Legislación Nacional para el Desarrollo de los Pueblos Indígenas.

7. La Carta Internacional de Derechos Humanos

8. Los tratados internacionales básicos en materia de derechos humanos

9. Otros instrumentos de derechos humanos de las Naciones Unidas

10. El derecho a la educación

11. Los derechos culturales

El Estado mexicano ha ratificado y se ha adherido a diversos tratados internacionales que reconocen el derecho a la educación, por lo tanto, existe la obligación de garantizar y aplicar este derecho en todo el territorio nacional, sin excepción de persona. En tanto que el derecho a la educación esté reconocido en todo el mundo, todos los niños y niñas pueden disfrutar de esos derechos, en los que el Estado tiene la responsabilidad de crear programas que puedan aplicarse para los niños con otras culturas, realizar actividades lingüísticas; pero en la realidad se vive algo distinto ha existido un descontrol y no se acatan las disposiciones de las normas internacionales y nacionales al no existir mecanismos de seguimiento para que se presten los servicios educativos a los niños migrantes. Alfredo Islas hace mención que "debe velarse por el acceso a la justicia en términos prácticos, lo que significa que la población debe tener acceso físico y económico, incluso mediante sistema de asistencia letrada" (Islas, 2018:54).

La responsabilidad de la construcción de programas y políticas públicas con una articulación más fluida en los actores de un sistema educativo con inclusión real, depende de muchos colaboradores, docentes, padres de familia sobre todo del Estado para que se pueda tener lo necesario que permita el fortalecimiento democrático de la educación, si bien es cierto que México trabaja para establecer políticas públicas relacionadas con la educación, todavía falta, en el caso de atención a los niños migrantes aun cuando en la Ley general de educación, en el artículo 8, fracción III, señala que se;

"contribuirá a la mejor convivencia humana, tanto por los elementos que aporte a fin de robustecer en el educando, junto con el aprecio para la dignidad de la persona y la integridad de la familia, la convicción del interés general de la sociedad, cuanto por el cuidado que ponga en sustentar los ideales de fraternidad e igualdad de derechos de todos los hombres, evitando los privilegios de razas, de religión, de grupos, de sexos o de individuos", (DOF, 2018).

En el tránsito por el territorio mexicano de las personas migrantes, en especial los niños por ser los más indefensos tienden a sufrir discriminación en la educación, contrario a los que señala la Constitución de la UNESCO y la Declaración Universal de Derechos Humanos, la UNESCO desde 1960 al adoptar la Convención que lucha contra la discriminación en la esfera de la enseñanza; de igual forma la Constitución Política de los Estados Unidos Mexicanos, (2019), en el artículo $3^{\circ}$., establece: “ la educación se basará en el respeto irrestricto de la dignidad de las personas, con un enfoque de derechos humanos y de igualdad sustantiva".

La postura de los diversos gobiernos pasados, ha sido tratar de modificar y reformar el contenido y estructura buscando crear políticas educativas que pueda dar cumplimiento a lo 
señalado por la Constitución Federal, pero al no dar seguimiento a los programas establecidos y fortalecer las debilidades, esto crea confusión y sobre todo no se tiene una postura firme que permita a la sociedad tener los servicios educativos de calidad para todos, por lo tanto tampoco llega a los niños migrantes quienes ni siquiera se les da el acceso de los sistemas educativos; en estudios recientes por el Instituto Nacional para la Evaluación de la Educación, denominado la política educativa de México desde una perspectiva regional, hace hincapié que sobre;

"La Reforma Educativa no es la agenda de política educativa de México. La Reforma es un conjunto de acciones que se suman a una agenda ya vigente, que dialoga con el conjunto de la política educativa y con su historia, con el fin de reorientarla hacia un horizonte definido -plasmado en el artículo $3^{\circ}$ constitucional- por la garantía del derecho a una educación de calidad. Los sistemas educativos están en un permanente proceso de reorientación y ajustes. La particularidad de las reformas, como se señalará más adelante, radica en que a fin de avanzar en esos cambios se necesita modificar aspectos estructurales del funcionamiento del sistema educativo. No es posible analizar en sí a la Reforma Educativa, sino en su capacidad de incidir sobre el flujo permanente de acción que define a la política educativa de México" (INEE-IIPE UNESCO, 2018:41).

Países en los que se vive el fenómeno de la migración como México, se han complicado al dar cumplimiento a la normatividad internacional y nacional relacionados con el derecho humano a la educación, la destinación de los recursos financieros y humanos para atender a los migrantes, aun no son suficientes para cumplir con la tarea y responsabilidad del Estado para crear estructuras y programas reales que puedan atender a los niños en calidad de migrantes, quienes por su condición no pueden ni siquiera disponer del derecho a la educación.

\section{CONCLUSIÓN}

La educación es base primordial para el desarrollo de cualquier país, además de que es un derecho humano, en la que los Estados han tratado de destinar recursos financieros, humanos, programas, estructuras, sin embargo les ha sido imposible acaparar la mayor parte de la población. En especial nuestro país México, que ha vivido diversos fenómenos sociales, como es el caso de la migración, tan solo por ser un vecino de un país con grandes capacidades económicas.

La migración en las últimas décadas es un punto rojo para México que ha luchado para poder cumplir con los compromisos contraídos al ratificar, adherirse a diversos instrumentos internacionales, que son normas protectoras de los derechos humanos; sin dejar fuera nuestra propia Constitución Federal, que desde su artículo 1, hace referencia sobre el respeto de los derechos humanos; aún falta demasiados programas, políticas públicas para hacer frente y permitir que toda persona disfrute en total sus derechos humanos.

La situación de los niños y niñas migrantes durante el recorrido por el territorio mexicano es muy difícil, sufren de todo tipo de violencia desde la discriminación hasta los abusos sexuales; desde ahí que han sufrido la falta de cuidados por ser personas débiles que no se pueden defender por si solos en su totalidad, mucho menos se les proporciona el derecho a la educación, derecho que también ellos pueden disfrutar. Las políticas públicas relacionadas al derecho a la educación no son suficientes, al no existir bases firmes que permitan a los niños migrantes que están detenidos por autoridades mexicanas recibir durante su estancia en las estaciones migratorias por lo menos educación básica, que les permita aprender a leer y a 
escribir para poder defenderse ante cualquier agresión, a desarrollarse como humano.

\section{BIBLIOGRAFÍA}

Constitución publicada en el Diario Oficial de la Federación el 5 de febrero de 1917, texto vigente, última reforma publicada DOF 15-05-2019, http://www.diputados.gob.mx/LeyesBiblio/ref/c peum.htm

Constitución de la Organización de las Naciones Unidas para la Educación, la Ciencia y la Cultura (1945) Aprobada en Londres el día 16 de noviembre de 1945. https://unesdoc.unesco. org/ark:/48223/pf0000226924 spa.page=7

Committee on Economic, Social And Cultural Rights (1999) CESCR General Comment No. 13: The Right to Education, en https://www.refworld.org/publisher,CESCR,GENERAL, , , 10.html

Corte Interamericana de Derechos Humanos Opinión Consultiva Oc-18/03 de 17 De Septiembre, Solicitada por los Estados Unidos Mexicanos (2003) Condición Jurídica y Derechos de los Migrantes Indocumentados, https://www.acnur.org/fileadmin/Documentos/BDL/2003/2351.pdf

Convención Americana sobre Derechos Humanos (1969) Pacto de San José, San José, Costa Rica 7 al 22 de noviembre de 1969, https://www.oas.org/dil/esp/tratados_b-32_convencion_americana sobre derechos humanos.htm.

Declaración Universal de Derechos Humanos (1948) Adoptada y proclamada por la Asamblea General en su resolución 217 A (III), de 10 de diciembre de 1948. https://www.ohchr.org/EN/UDHR/Documents/UDHR_Translations/spn.pdf

Islas Colín, A. (2018) Migrantes y Refugiados, protección de derechos humanos. México: Porrúa.

Islas Colín, A. (2018) "El derecho al agua de los pueblos indígenas: decreto de la región hidráulica, número 30, Grijalva - Usumacinta", en A. J. Martínez Lazcano (Dir.) Derechos Humanos: la transformación de cultura jurídica. Colombia: Ediciones Nueva Jurídica.

Informe anual de actividades (2018) Comisión Nacional de Derechos humanos (CNDH) http://informe.cndh.org.mx/menu.aspx?id=30055

Instituto Nacional para la Evaluación de la Educación, INEE-IIPE UNESCO (2018) La política educativa de México desde una perspectiva regional. México: Publicación del Instituto Nacional para la Evaluación de la Educación

Instituto Nacional de Migración (s.f.) "Conoce los programas del INM de protección al migrante" en https://www.gob.mx/inm/articulos/conoce-los-programas-del-inm-de-proteccion-almigrante? idiom $=$ es

Ley General de Educación (2018) Diario Oficial de la Federación el 13 de julio de 1993, texto vigente, última reforma publicada DOF 19-01-2018, https:/www.sep.gob.mx/work/models/ sep1/Resource/558c2c24-0b12-4676-ad90-8ab78086b184/ley general educacion.pdf

Ley General de Migración (2016) Última Reforma DOF 21-04-2016. www.gobernacion.gob.mx/es $\mathrm{mx} / \mathrm{SEGOB} /$ Ley de Migracion UPM

Missing Migrant Project (2017) Migrant Fatalities Worldwide. New York: Missing Migrant Project. (Consultado el 10 de marzo 2019), en: https://missingmigrants.iom.int/latest-global-figures

Naciones Unidas (s.f.) Derechos Humanos. Oficina del Alto Comisionado. ¿Qué son los derechos humanos? https://www.ohchr.org/SP/Issues/Pages/WhatareHumanRights.aspx

ONUMÉXICO (2015)" Objetivos del desarrollo sostenible", en http://www.onu.org.mx/agenda2030/objetivos-del-desarrollo-sostenible/

Organización Internacional para las Migraciones (s.f.) Derecho Internacional sobre Migración, https://publications.iom.int/system/files/pdf/iml 7 sp.pdf

Prontuario sobre poblaciones migrantes en condiciones de vulnerabilidad es producto de la Dirección General Adjunta del Centro de Estudios Migratorios de la Unidad de Política Migratoria de la Secretaría de Gobernación, en http://www.politicamigratoria.gob.mx/es mx/SEGOB/ Consjo_Consultivo

Redodem (2016) Migración en Tránsito por México: rostros de una crisis humanitaria internacional. México: Red de Documentación de las Organizaciones Defensoras de Migrantes. 
Ahmed, A. y Dickerson, C. (2018) "La caravana migrante enfrenta a México con su propia imagen y con Estados Unidos”. The New York Times https:/www.nytimes.com/es/2018/10/23/caravanamigrante-mexico-estados-unidos/.

Unidad Política Migratoria, UPM (2016) Boletín mensual de estadísticas migratorias. México: Unidad de Política Migratoria

\section{Breve currículo:}

\section{Rosa Cornelio Landero}

Doctora en Métodos de Solución de Conflictos y Derechos Humanos, PNPC-CONACYT. Profesora Investigadora de Tiempo Completo con perfil deseable en la División Académica de Educación y Artes de la Universidad Juárez Autónoma de Tabasco. Maestra en Administración Pública por la Universidad Juárez Autónoma de Tabasco, Licenciada en Administración, Licenciada en Derecho, integrante del grupo de investigación Intervención socioeducativa hacia los Derecho Humanos y la Responsabilidad Social. 